Journal of

Online and Distance

Learning

(JODL)

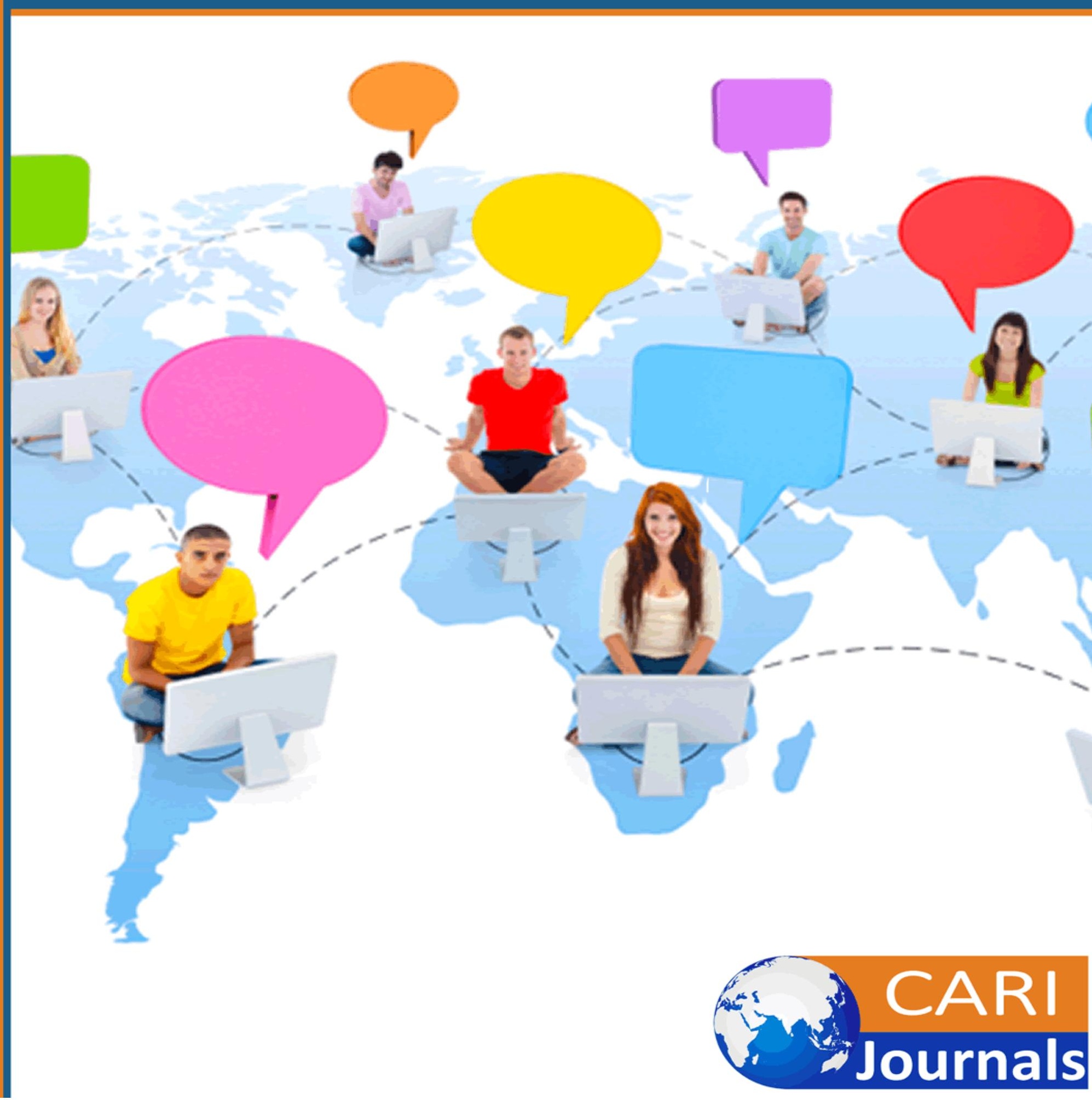




\title{
INFLUENCE OF INSTITUTIONAL RELATED ON CHOICE OF TECHNOLOGY FOR THE DEVELOPMENT OF INSTRUCTIONAL MATERIALS FOR DISTANCE EDUCATION.
}

\author{
Dr.James Kimani \\ Department of Education. Egerton University \\ Corresponding author email:James@ cari.org
}

\begin{abstract}
Purpose: no one technology can support all types of teaching and learning at a distance - the most effective approach is to combine a range of technologies. Using multiple technologies ensure that all learning styles are catered for and that significant opportunities for interaction between the learner and the tutor are provided. The general objective of the study was to institutional related on choice of technology for the development of instructional materials for distance education.
\end{abstract}

Methodology: The paper used a desk study review methodology where relevant empirical literature was reviewed to identify main themes and to extract knowledge gaps.

Findings: From the study findings, it is concluded that most of learner support services offered to distant learners were not good enough to support the learners effectively. Secondly, the students and the administrators were of the view that there were learner support services that were very vital to distant learners. Thirdly, the students and the administrators were of the general view and in agreement that the learner support services offered were necessary. However, since the students indicated that majority of the services on offer were poor across the institutions under the study, there is need to improve and make them better. Learning through experience influences the creation of new values which become attitudes that have a strong impact on teacher's behavior towards e-learning technology.

Recommendations: The study recommends that is a need availability of ICT infrastructure, the absence of inadequacy of which will totally hamper the idea of e-learning adoption in universities. There should be provision of computers and high bandwidth to enable the easy flow of classes online. If the high ICT infrastructure for e-learning is unavailable, the sequential use of predecessor distance learning technologies from correspondence courses to radio, TV, CD-ROM, Internet and World Wide Web is recommended. Such a sequential use of predecessor distance learning technologies is poised to leverage the experience into a significant use of learning.

Keywords: influence, institutional related factors, choice of technology, development of instructional materials, for distance education 


\subsection{INTRODUCTION}

\subsection{Background of the Study}

Institutional factors belong to a group of extrinsic motivational factors influencing academic teacher's acceptance of e-learning technology. Numerous study results indicate that factors which influence academic teachers differ depending on the current phase of e-learning introduction into the academic institution in question. One of the key factors is the capacity and reliability of the ICT infrastructure (Nanayakkera , 2015). In practice, instructors frequently list the following conditions as obstacles: access to the computer classroom, number of computers in a classroom, computer network, Internet (access and speed) (Osika, 2019). After solving the problem of infrastructure, there are other negative factors that influence eLearning application. Thus, perceived adequacy of support (for example technical, pedagogical, personnel), as facilitating circumstance, has an important impact on applying e-learning in distance education (Timothy, 2019).

Availability of information about the manner of applying eLearning technology in distance education process can positively influence instructors' adoption of e-learning (Kundi., 2010). Since introduction of distance learning technology into academic institutions causes changes in structure, policies and organizational culture, it also brings about changes in organizational learning. Keller (2009) proved that organizational culture has the strongest impact on distance learning technology integration by academic instructors through the level of organizational learning, thus the expected effort and observability have stronger connection with the lower level of organizational learning, while social influence and facilitating circumstances relate to the higher level of organizational learning. Numerous authors confirmed that institutional strategy is an important obstacle in adopting distance learning technologies (Keller, 2019).

Teacher's academic freedom and organizational culture of teaching also represent obstacles in elearning acceptance (Keller, 2009). After accepting e-learning technology, instructors still point out the following obstacles in its use: work overload, question of property, required resources, professional growth and management (Marwan, 2010). The academic institution's management has a great role in introducing and developing e-learning. Gautreau (2012) confirms the importance of adequate support and training factors, but also proves that reward and encouragement system and recognition of accomplishments are very important motivational factors in teachers adopting and developing e-learning. However, even after removing many of the aforementioned obstacles, numerous study results indicate that time is the crucial factor that needs to be invested when changing to blended distance learning model, and it is connected to acquiring new knowledge, adjusting and implementing the course material to e-learning system, as well as to the lack of time for the requirements of the scientific research (Stacey , 2017).

Instructor's personality is a powerful intrinsic motivational factor which influences elearning technology acceptance. It represents a set of characteristics which make every teacher unique in education process and it is strongly influenced by the surroundings. The most commonly studied teacher's features are: self-efficacy and anxiety, more often approached from the technical aspect. Computer anxiety is closely connected to the teacher's attitude, author suggests the possibility of understanding computer self-efficacy as a construct of perceived ease of use (Timothy, 2019). 
Malik et al. (2010) mention teacher's organizational commitment as an important factor in quality teaching process and Baia (2019) confirmed the influence of commitment to the pedagogical quality on the e-learning technology acceptance. Teacher's personality is evident through teaching and learning style applied in the education process and which includes certain teaching methods and techniques, and represents a mechanism responsible for quality conveyance of the educational content influencing the student success (Grasha, 2014). Changes in the teacher's belief, attitude and values influence the teaching style. Lucas \& Wright (2009) predicts the possibility of connection between teaching style and the attitude towards the use of e-learning technology. Dugas (2016) determined a slight connection of teaching style and the degree of innovation with accepting e-learning technology. Apart from the teacher's personality, great importance lies in the demographic and situational variables. The experience with LMS and computer experience are strong motivators in teachers' acceptance of e-learning (Gautreau, 2011). In his research Timothy (2019) did not find significant link between attitude, age and gender, which contradicts the hypothesis by Houtz and Gupta, Cully et al. (Timothy, 2019), he found a significant difference in the attitudes of the female computer users. However, Marwan and Sweeney (2010) point out to a significant connection between gender, department and academic title with the teacher's attitude towards elearning technology. Academic title and years of work experience influence the commitment to the pedagogical quality which influences acceptance of e-learning technology (Baia, 2019).

Most University e-Learning programmes have been designed to increase access to higher education, especially for non-traditional students. In a recent survey on the importance of various goals to institutions' distance education program (a high proportion of which use online technology as a primary or supporting medium of instruction), two out of three United States of America fouryear public institutions indicated that increasing student access was a very important goal; either by "making courses available at convenient locations" (72\%), or by "reducing time constraints for course taking" (66\%), (Demuyakor, 2020). The corresponding figures for four-year private institutions were also high (65\% and $61 \%$ respectively). In Europe, as well, there is abundant evidence to show that widening access to their programmes - and to their related academic resources - is an important objective of many university e-learning strategies; reaching new groups of students (women and other marginalised groups) is an additional and closely related goal (UNESCO, 2000). According to (Demuyakor, 2020), Open and Distance Learning offers opportunities for countries to meet the new and changing demands for education and training. Open and Distance Learning is both complementary and under certain circumstances an appropriate substitute for the face-to-face methods that still dominate most educational systems. The advantages of Open and Distance Learning are seen more in terms of the learner through more freedom of access, and thereby a wider range of opportunities for learning and qualification. The barriers that may be overcome by distance learning include not only geographical distance, but also other confining circumstances, such as personal constraints, cultural and social barriers and lack of educational infrastructure (Ali, 2020).

UNESCO (2012) define distance education as any educational process in which all or most of the teaching is conducted by the teacher removed in space and/or time from the learner, with the effect 
that all or most of the communication between the two is through an artificial 3 medium, either electronic or print. According to Abdarahim, (2018) distance education implies that the majority of educational communication between the teacher and the students occurs non-contiguously (at different times and at separate places - separating the instructor tutor from the learner). It must involve two-way communication for the purpose of facilitating and supporting the educational process. It uses technology to mediate the necessary two-way communication. According to Nzuki, (2015) the purpose of distance education is based on the principle of equality of opportunity for all. This is largely the mission of distance education which emphasizes the expansion of education for self - employment and for quality life. The philosophy of distance education also emphasizes the need for individually educated population that can contribute to social and economic development of the society. They contend, distance education is particularly attractive and affordable to a majority of adult learners.

According to Levin (2018), distance learning is a viable investment for adult learners who may have only had access to lower level or non-degree courses. Distance education is also helping universities serve a formerly unservable audience, Levin (2018). Ghosh,(2018) report that distance education appeals to adult learners since they do not have to give up their jobs during study, they do not have to be away from their families for a long period of time, or have to worry about lecturers and sessions and have an opportunity to attend residential sessions for shorter periods. According to Phelan, (2020), distant learners always enjoy flexibility in terms of choosing the place and time of study. According to Common Wealth of Learning (2015), adult learners seek higher education through distance learning primarily to get a job, gain a better job or a promotion, and earn a higher income.

For employers, open and distance learning offers the possibility of organizing learning and professional development in the workplace itself, which is often more flexible and saves costs of travel, subsistence etc. The use of distance learning often puts both the firm and employees in a position of co - investment (of money and time) in the pursuit of common goals, based on shared values and culture. It increases productivity and supports the development of communication and other work-related skills. With sufficient numbers of employees being trained, open and distance learning is usually cost-effective. Other advantages for the employer include the increased availability of the employee during the course of the training programme, and the portability of training programmes and processes (UNESCO, 2020). Distance learning also serves many good purposes from an institution's point of view. Through technology, students who live great distances from an institution can be served. Adult learners can enroll in college course work at convenient times and in more convenient locations. College and university administrators recognize that instructors can teach more students without increasing the need for additional staff. Full-Time- Enrollment increases with distance education, thus, providing schools with additional state income with little additional expense (Major, 2017). The place of distance education in increasing access to higher education worldwide cannot be understated.

According to Kanwar, (2017), higher education has expanded remarkably in recent decades. Growth is, by all means, faster than anticipated. Van der Wende, (2018) reports that 120 million students are expected to be enrolled in higher learning institutions worldwide by 2020, but that number has already been achieved. Santiago, Tremblay, Basri, \& Arnal, (2018) report that in 2004, 
132 million students were enrolled worldwide, up from 68 million in 1991. Average annual growth from 1991 to 2004 was 5.1 per cent. Most of this growth has been in Africa, Asia, Latin America and the Caribbean, the Arab countries, and in Eastern and Central Europe. UNESCO, (2019) reports that distance education represents an area of enormous potential for higher education systems around the world struggling to meet the needs of growing and changing student populations. For several decades the sector has been dominated by largescale 'open' universities (Indira Gandhi National Open University in India counts 1.8 million students). The University of South Africa UNISA claims to be the continent's premier distance learning institutions with approximately 250,000 students. The African Virtual University works across borders and language groups in over 27 countries Cambridge UK. UNESCO (2009) further notes that much of the appeal of distance education is attributed to its ability to accommodate the needs of a wide variety of learners (students located far from educational centers, employed adults, women who are attempting to balance family and school commitments) and even the incarcerated.

According to Mehrotra, Hollister, and McGahey, (2011), distance education, is not a future possibility for which higher education must prepare, it is a current reality creating opportunities and challenges for educational institutions; a reality offering students expanded choices in where, when, how, and from whom they learn; a reality making education accessible to ever larger numbers of persons. Lockwood, 1993 contends that since the learners and the instructors are geographically isolated, distance learning relies largely on electronic devices and print materials for instructional delivery. Mbwesa (2010) Journal of Continuing Open and Distance Education, states that the extent, to which teachers perceive a certain pedagogic approach as being effective, will influence greatly the extent to which they appreciate and adopt new innovations. Quoting from her research on the use of WEDUSOFT software as a learning management system, it can be noted that many of her respondents perceived it as an effective management learning system in the University of Nairobi. Gakuu, and Kidombo, (2010) in the same journal on pedagogical integration of ICT in curriculum delivery notes that it is influenced by the ownership of the institutions, ICT policy and the manager's level of ICT skills. That the Kenya government should develop and implement as ICT policy on education.

\subsection{Statement of the Problem}

Stakeholders, policy and decision-makers are concerned with the large number of students who are qualifying to join the universities but are missing the chance because of the limited resources available. The opening up of private universities has not been able to absorb all these students either. This leaves many eligible people to exploit open, distance and e-learning mode of study. Besides, there has been an accumulation of students who had joined other tertiary colleges hoping that doors would be opened up for them to pursue careers of their dreams. Therefore open, distance and e-learning mode of study remains one of the best available options which is bound to increase access to higher education through the establishment of adequate learner support service. However, studies done in this area such as by Juma (2016) and Anyona (2019) were mainly concerned with the challenges of distance learning to the decision-makers and not the students. Jurich (2020) associates the slow and marginal uptake of technology in distance learning to faculty "fear of technology" that limits the faculty's ability to take full advantage of learning technologies in support of distance learning. Merisotis \& Phipps, (1999) also note that students may be 
inexperienced with using technology, particularly educational technology. This study therefore seeks to explore influence of institutional related factors on choice of technology for the development of instructional materials for distance education.

\subsection{Objectives of the Study}

The general objective of the study was to determine influence of institutional related factors on choice of technology for the development of instructional materials for distance education.

\subsection{Justification and Significance of the Study}

The study may help open, distance and e-learning programme developers to incorporate more responsive and effective learner support services as they develop programmes as well as reevaluate the learner support services being offered in their institutions. Secondly, the Commission for University Education (CUE) may use the findings from the study to ensure that essential learner support services are put in place before approving proposals for courses of study submitted by institutions of higher learning offering open, distance and e-learning programmes. Thirdly, the information and knowledge gained from the study may help the learners to know the type of learner support services they expect as they enroll for courses in open, distance and e-learning and lastly, the study may create ground for further research.

The findings of the study will also create a basis for future research on technology in distance education in globally. This research is expected to be useful to in private institutions such as those offering continuous in house on job training such as banks, mobile staff in order to improve manpower service provider skills, universities offering adult learning programs. Cooperative societies offering entrepreneurship knowledge to its retiring members, government ministries offering programmes that aims at improving staff performance, international organizations offering further education support in developing countries, among stakeholders in education sector.

\subsection{LITERATURE REVIEW}

\subsection{Theoretical review}

Two theories were found to be relevant in to determine influence of institutional related factors on choice of technology for the development of instructional materials for distance education. The theories that were found to best inform the research constructs are system approach model, (Ayot, 1987) and Technology Acceptance Model Theory (Vankatesh, 2008).

\subsubsection{System Approach Model}

Systems approach model developed by Ayot (1987) whereby a system is made up of components which have sub-systems that merge to make the supra system (Richey, 1986). Romiszoski (1981) asserts that the components in a system must work in harmony in order to achieve a common goal. These components are the input and the output (Were, 2003). Every system must have a goal which it has set out to achieve as well as a provision of feedback that assesses the system success level. Once a system starts working, its output is guaranteed in quantity and quality whereby the feedback 
ensures that the system is rectified in time in case of a problem (Ayot \& Patel, 1987). This approach comes in handy in that it is scientifically based in reference to its design, hence improving the instruction of a programme (Gagne, 1987). In this study, every institution offering open, distance and e-learning must have input which include the teaching and learning needs, access of information needs and social and personal needs. All the three categories of learner support services are incorporated by institutions to assist the learners through the programme. The expected output is adequate learner support service whereby $50 \%$ and above of the students are expected to be satisfied with any learner support service offered by their respective institutions. Where the learner support service does not meet the 50\% threshold then there is need to re-evaluate the essence of offering the specific learner support service and make interventions to improve on the particular learner support service to make it more helpful to the learners.

\subsubsection{Technology Acceptance Model Theory}

This study adopted the Technology Acceptance Model Theory (TAM) of Vankatesh \& Bala (2008) which is greatly referred to as Information System Theory (IST). This theory shows how the users take time to accept and use any new technology disposed to them. Vankatesh and Balla (2008) emphasize that technologies which are new like personal computers or any other, are complicated from the beginning and there exist an element of uncertainty in the minds of the maybe makers of decisions with respect to adopting them successfully. In this situation people form intentions and attitudes towards making effort in learning how to use the technology that is new before initiation of efforts which are directed at using. Attitudes towards using and the intentions to use can be poorly-formed or lack conviction or else can only occur only after preliminary striving in learning how to use the new technology that evolves. This means that the real usage may not have immediate or direct consequence of such intentions and attitudes. The Technology Acceptance Model Theory continues to state that subject norms, perceived behavioral control and attitudes shape every individual intention it takes in engagement in a specific time and place. Behavioral intentions are influenced by the attitudes of individuals basing on pre-expected outcomes in terms of risks and benefits not yet seen or experienced. Behaviour depends on both motivation (intension) and (behavioral control). The six constructs influencing a person's behavior are namely; attitude to evaluate, strength of intension, degree of approval (are many people benefiting?), social norms-(what is the trend?) Power of impediments (can I get over or not?), perceptions- (easy or difficult?).This theory will add to the study as it helps in evaluation of adoption of modern online learning as transits from the traditional learning process

\subsection{Empirical Review}

Laichena , (2017) conducted a study set out to ascertain the types of learner support services offered to open, distance and e-learning students as well as identify learner support services that the students and the administrators felt were essential for effective learning. The study also intended to establish the attitudes of the users of open, distance and e-learning programmes on the learner support services offered and identify the factors that influence learner support services offered in open, distance and e-learning programmes in selected public universities in Kenya. The study limited itself to fourth year students undertaking a bachelor's degree programme only. This study was guided by the systems approach model whereby the types of learner support services offered by an institution enhances the success of open, distance and e-learning programmes 
through provision of adequate learner support services. Literature reviewed on the categories of services such as teaching and learning needs, access of information and personal and social needs (independent variables) showed that they determine the overall satisfaction of learner support services (dependent variable) offered. The study adopted a descriptive survey design. Purposive sampling was used to select three public universities offering open, distance and e-learning programmes, namely Egerton University, Kenyatta University and the University of Nairobi. Further, purposive sampling method was also used to select three study regions where each of the three universities had a study centre. A sample size of 329 fourth year students in the selected universities was arrived at using tables instituted by Morgan and Krejcie (1970). Stratified sampling technique was used to get a representation of students from each university while convenience sampling was used to select the students at each study centre from each university. All the administrators (directors and coordinators) were used in the study. The study instruments (interview schedules and questionnaires) were constructed to help in data collection. The data collected was coded, analysed and tabulated using the SPSS version 20 programme. Results were presented in form of frequency distribution tables and graphs. The study established that students rated majority of learner support services offered by their institutions across the three universities as poor while the administrators indicated that the services offered were good. However, the students and the administrators were of the opinion that there were essential learner support services that were very necessary to open, distance and e-learning students. Further, there was a consensus by the students and the administrators that the services offered were necessary though they needed to be improved. Lastly, the study found out that the administrators were aware of the essential learner support services but were limited by other factors that were beyond their control. The study recommends that; institutions offering open, distance and e-learning programmes should constantly assess the value of learner support services offered by constantly seeking the students ${ }^{\text {ee }}$ opinion and offer few but essential learner support services that are of high quality, adequate, of good quality and satisfactory to the students.

Kyutha, 2014 who conducted a study focusing on finding out how Open Distance and e-Learning is designed and implemented in a rural and remote area, the potentials it has as a mode of delivering higher education and increasing female students from marginal areas to higher education. The study design employed a case study. Majorly qualitative data was generated and also quantitative data to address the study objectives. Purposive sampling was used for the study. Self-administered questionnaires were given to all the students enrolled at the centre, structured interviews were conducted on initiators of the project, project coordinators at Marsabit and Kenyatta University, Executive Director of Kenya Education Network Trust, Lecturers who interacted with the students, and Focus Group Discussions were conducted for a few selected students and community leaders. The data was mainly analyzed through coding and categorization and entailed deep descriptions using words to represent information as obtained from respondents. Quantitative data analysis entailed basic descriptive statistics which were represented in tables and percentages. The data obtained showed that when well designed and fully sponsored Open Distance and e-Learning is more suitable approach to increasing access to female students to university from marginal areas. The Open Distance and e-Learning initiative is acceptable by both students and the community since the women can learn within their cultural setting. The study also showed that the implementation was not proper. The students lacked variety of reading materials, they needed more 
face- to- face interaction with lecturers, they needed a wider variety of courses to be offered since only Bachelor of Education (Arts) courses were offered. In terms of support, a broader financial support system was needed for them to complete their courses. There is a need for research to be conducted to establish the most promising package of interventions to be implemented to ensure greater access, high enrolment and completion rates of enrolled students

Nderitu, (2013) carried a study to find out the effect of time management of academic performance a study was carried out. A total number of 650 students were selected using stratified random sampling technique. This sample was taken from 4,500 University of Nairobi students who were registered for B.Ed degree in different levels of study in the school of continuing and distance Education. A mixed mode method approach was used in data collection. Correlational research design was employed in data analysis. Pearson correlations were used to establish if there was a relationship between time management and academic performance. The analysis indicated a strong relationship between time management and academic [ $\mathrm{r}=0.569]$. The value of $\mathrm{r} 2=0.324$, indicated that time management accounts for about $32.4 \%$ of the variation in average performance.

Mwiti,(2012) conducted a study to investigate the factors that affect learning of learners with visual impairments learning through distance education; a case of Kenya Institute of Special Education. The study was guided by three research objectives; such as to investigate the effect of teaching and learning strategies in promotion of learning of learners with visual impairments learning through distance education; a case of Kenya institute of special education, to investigate the effect of the environmental modification and adaptation in learning of learners with visual impairments learning through distance education; a case of Kenya institute of special education, and to establish the extent to which learner support services available influence learning of learners with visual impairments learning through distance education; a case of Kenya institute of special education. The target population was drawn from the face to face tutorial centers, where the learners with visual impairments attend their tutorial sessions. The learners in these centers represented all other learners in the country in other institutions of higher learning offering studies through distance education mode. A survey research design was used for this study. The factors that affect learning of learners with visual impairments learning through distance education were studied based on the three research objectives. The data was processed using statistical package for social science. The results of the findings in the study revealed that Kenya institute of special education had tried in providing accessible education to learners with visual impairments learning through distance education mode. However, there are various aspects that require improvements such as provision of all learning materials in braille and large print, audio cassettes, recorded lectures, and closed circuit televisions to enhance learning of students with visual impairments, studying through distance education. The study also found out that there is need to improve on environmental modification and adaptation and also need to improve on learner support services at the face to face tutorial centres. The researcher recommends that KISE should provide appropriate and adequate teaching and learning materials, ensure that students are provided with appropriate and conducive learning environments and that they are provided with adequate learner support services by professional counselors who understands and knows how to handle students with visual impairments 
Kitua, (2012) conducted a study aimed at identifying the factors that influence the use of the internet in learning at the Meru extra mural center. The study strived to determine the use of the internet as a channel of communication used in learning as well as the social, student and university related factors affecting the use of this channel of communication. The researcher employed descriptive survey design, gathering information from distance education students and the staff at the Meru extra mural centre using questionnaires. Quantitative data was analyzed according to the objectives using descriptive statistics to show a comparison between factors while inferential statistics specifically the independent sample t-test was used to determine the relationships between the dependent and the independent variables. Data was then presented in form of tables and charts for interpretation. The social factors identified were found not to have significant effect on frequency of use of internet by distance learners while the university and learner factors had significant effects on use of internet by distance learners. The researcher recommends that the university should offer computer training for all students and allow free access to university computers and internet.

Kubai, (2011) conducted a study on factors influencing health workers satisfaction with training through distance learning mode of study. The objectives of the study were to determine how accessibility to technology, Learner education background, delivery modes, efficacy with technology and gender influences on learner satisfaction with distance learning. This study employs the case study research design to be able to gather particular data on the health workers satisfaction with training through distance learning mode of study. The sample consisted of $10 \%$ of the total population, that is eighty seven students $(n=87)$. Systematic random sampling procedure was used to arrive at the sample of students. To facilitate fast and convenient collection of data, questionnaires were used. The collected data was recorded and analyzed using both qualitative and quantitative methods. SPSS (Statistical Package for Social Science) was used to aid the process of data analysis. The findings indicated that both slow internet connectivity and lack of internet connectivity influenced the accessibility to technology and therefore influenced on learner satisfaction with distance learning. From the study results it was clear that learners' educational background was a key factor that contributed to learner's level of satisfaction in distance learning. Pertaining gender it was revealed that in AMREF Training center female students had higher representation in distance learning compared to male students. Based on these study findings, recommendations drawn include: Distance learning institutions should provide learner support services in form of physical facilities, such as libraries, ICT, provide access to course resources as mechanisms important to student learning and development.

\subsection{Research gaps}

Geographical gap is a knowledge gap that considers, the untapped potential or missing/limited research literature, in the geographical area that has not yet been explored or is under-explored. For instance, Mwiti, (2012) conducted a study to investigate the factors that affect learning of learners with visual impairments learning through distance education; a case of Kenya Institute of Special Education. A survey research design was used for this study. The results of the findings in the study revealed that Kenya institute of special education had tried in providing accessible education to learners with visual impairments learning through distance education mode. The study presented a geographical gap as it was done in Kenya while our current study 
sought to evaluate influence of institutional related factors on choice of technology for the development of instructional materials for distance education.

Methodological gap is the gap that is presented as a result in limitations in the methods and techniques used in the research (explains the situation as it is, avoids bias, positivism, etc. Laichena , (2017) conducted a study set out to ascertain the types of learner support services offered to open, distance and e-learning students as well as identify learner support services that the students and the administrators felt were essential for effective learning. The study adopted a descriptive survey design. Purposive sampling was used to select three public universities offering open, distance and e-learning programmes, namely Egerton University, Kenyatta University and the University of Nairobi.The the study found out that the administrators were aware of the essential learner support services but were limited by other factors that were beyond their control. The study recommends that; institutions offering open, distance and e-learning programmes should constantly assess the value of learner support services offered by constantly seeking the students ${ }^{\text {ee }}$ opinion and offer few but essential learner support services that are of high quality, adequate, of good quality and satisfactory to the students. The study presented a methodological gap as it was subjected to descriptive research design while our current study adopted a desktop literature review method.

Conceptual gap arises because of some difference between the user's mental model of the application and how the application actually works. Nderitu, (2013) carried a study to find out the effect of time management of academic performance a study was carried out. A total number of 650 students were selected using stratified random sampling technique. Correlational research design was employed in data analysis. Pearson correlations were used to establish if there was a relationship between time management and academic performance. The analysis indicated a strong relationship between time management and academic $[\mathrm{r}=0.569]$. The value of $\mathrm{r} 2=0.324$, indicated that time management accounts for about $32.4 \%$ of the variation in average performance. The study presented a conceptual gap as it sought to evaluate influence of institutional related factors on choice of technology for the development of instructional materials for distance education.

\subsection{METHODOLOGY}

The study adopted a desktop literature review method (desk study). This involved an in-depth review of studies related to influence of institutional related factors on choice of technology for the development of instructional materials for distance education. Three sorting stages were implemented on the subject under study in order to determine the viability of the subject for research. This is the first stage that comprised the initial identification of all articles that were based on influence of institutional related factors on choice of technology for the development of instructional materials for distance education for distance education from various data bases. The search was done generally by searching the articles in the article title, abstract, keywords. A second search involved fully available publications on the subject on influence of institutional related factors on choice of technology for the development of instructional materials for distance education. The third step involved the selection of fully accessible publications. Reduction of the literature to only fully accessible publications yielded specificity and allowed the researcher to focus on influence of institutional related factors on choice of technology for the development of 
instructional materials for distance education which was split into top key words. After an in-depth search into the top key words (influence, institutional related factors, choice of technology ,development of instructional materials, distance education), the researcher arrived at 6 articles that were suitable for analysis. The 6 articles were findings from Laichena, (2017) who conducted a study set out to ascertain the types of learner support services offered to open, distance and elearning students as well as identify learner support services that the students and the administrators felt were essential for effective learning. The study adopted a descriptive survey design. Purposive sampling was used to select three public universities offering open, distance and e-learning programmes, namely Egerton University, Kenyatta University and the University of Nairobi. The study established that students rated majority of learner support services offered by their institutions across the three universities as poor while the administrators indicated that the services offered were good.

Kyutha, 2014 who conducted a study focusing on finding out how Open Distance and e-Learning is designed and implemented in a rural and remote area, the potentials it has as a mode of delivering higher education and increasing female students from marginal areas to higher education. Purposive sampling was used for the study. The study also showed that the implementation was not proper. The students lacked variety of reading materials, they needed more face- to- face interaction with lecturers, they needed a wider variety of courses to be offered since only Bachelor of Education (Arts) courses were offered

Nderitu, (2013) who carried a study to find out the effect of time management of academic performance a study was carried out. A total number of 650 students were selected using stratified random sampling technique. Correlational research design was employed in data analysis. Pearson correlations were used to establish if there was a relationship between time management and academic performance. The analysis indicated a strong relationship between time management and academic [ $r=0.569]$. The value of $r 2=0.324$, indicated that time management accounts for about $32.4 \%$ of the variation in average performance.

Mwiti, (2012) who conducted who a study to investigate the factors that affect learning of learners with visual impairments learning through distance education; a case of Kenya Institute of Special Education. A survey research design was used for this study. The results of the findings in the study revealed that Kenya institute of special education had tried in providing accessible education to learners with visual impairments learning through distance education mode.

Kitua, (2012) who conducted a study aimed at identifying the factors that influence the use of the internet in learning at the Meru extra mural center. The researcher employed descriptive survey design, gathering information from distance education students and the staff at the Meru extra mural centre using questionnaires. The social factors identified were found not to have significant effect on frequency of use of internet by distance learners while the university and learner factors had significant effects on use of internet by distance learners. The researcher recommends that the university should offer computer training for all students and allow free access to university computers and internet. 
Kubai, (2011) who conducted a study on factors influencing health workers satisfaction with training through distance learning mode of study. This study employs the case study research design to be able to gather particular data on the health workers satisfaction with training through distance learning mode of study. From the study results it was clear that learners' educational background was a key factor that contributed to learner's level of satisfaction in distance learning

\subsection{SUMMARY, CONCLUSION AND POLICY IMPLICATION FOR FURTHER STUDY}

\subsection{Summary}

Pre-course study skills training is a key learner support service to any student enrolled under open, distance and e-learning mode of study. Sewart (1993) noted that students entering the programme without having pre-course study skills experience anxiety, frustration, and often fail in their academic work. An indicator that in order to succeed, learners need to have pre-course study skills required for effective teaching and learning which must be well taught and supported. Therefore, institutions offering open, distance and e-learning must ensure that pre-course study skills are offered to students during orientation on how to access electronic resources such as course outlines, study materials and other related resources that are useful in their learning.

\subsection{Conclusion}

From the study findings, it is concluded that most of learner support services offered to distant learners were not good enough to support the learners effectively. Secondly, the students and the administrators were of the view that there were learner support services that were very vital to distant learners. Thirdly, the students and the administrators were of the general view and in agreement that the learner support services offered were necessary. However, since the students indicated that majority of the services on offer were poor across the institutions under the study, there is need to improve and make them better. Learning through experience influences the creation of new values which become attitudes that have a strong impact on teacher's behavior towards e-learning technology. Therefore, the attitude and values are singled out as a separate category as well, linking together certain factors that influence them. Because of the manner of academic teaching process, the most commonly used is blended learning model where a course instructor chooses the e-learning technology based on certain elements. The practice has shown that creating a blended learning environment is not easy and that course instructors have problems in many stages of designing the virtual learning environment, from the analysis of the course requirements, analysis of the student requirements, application of instructional design model, elearning technology use, not understanding the concept of the quality of e-learning process and many other factors.Lastly, although the administrators were aware of the necessary learner support services required, they were constrained by other factors beyond their control.

\subsection{Recommendations}

Institutions offering open, distance and e-learning programmes should constantly evaluate the value of learner support services offered by seeking the students ${ }^{\text {ee }}$ opinion so as to ensure that services offered are beneficial to the majority of students. Institutions should strive to offer few 
but essential learner support services such as printed materials (modules), online library, face to face interaction, online interaction and e-learning materials that are of high quality and satisfactory to their students instead of many services that do not meet the students ${ }^{\text {ee }}$ expectations. All the learner support services offered by various institutions were seen to be necessary. However, it is important to ensure that they are satisfactory to majority of the students.

\subsection{REFERENCES}

Abdrahim, N. A. (2018). Practices in Malaysian Higher Education. International Journal of Academic Research in Business and Social Sciences, 8(12).

Ali, W. (2020). Online and remote learning in higher education institutes: A necessity in light of COVID-19 pandemic. Higher Education Studies, 10(3), 16-25.

Ali, Wahab. "The Efficacy of Evolving Technology in Conceptualizing Pedagogy and Practice in Higher Education." Higher Education Studies 9, no. 2 (2019): 81-95.

Dawson, B. A., \& Fenster, J. (2015). Web-based social work courses: Guidelines for developing and implementing an online environment. Journal of Teaching in Social Work, 35(4), 365-377.

Demuyakor, J. (2020). Coronavirus (COVID-19) and online learning in higher institutions of education: A survey of the perceptions of Ghanaian international students in China. Online Journal of Communication and Media Technologies, 10(3), e202018.

Effendi, H., Soenarto, S., \& Sofyan, H. (2015). The effectiveness of web-based interactive blended learning model in electrical engineering courses. REiD (Research and Evaluation in Education), 1(2), 175-185.

Garcia, I., Guzmán- Ramírez, E., \& Pacheco, C. (2015). CoLFDImaP: A web- based tool for teaching of FPGA- based digital image processing in undergraduate courses. Computer Applications in Engineering Education, 23(1), 92-108.

Ghosh, D., Gupta, A., \& Levine, S. (2018). Learning actionable representations with goalconditioned policies. arXiv preprint arXiv:1811.07819.

Gray, J. A., \& DiLoreto, M. (2016). The effects of student engagement, student satisfaction, and perceived learning in online learning environments. International Journal of Educational Leadership Preparation, 11(1), n1.

Kapasia, N., Paul, P., Roy, A., Saha, J., Zaveri, A., Mallick, R. \& Chouhan, P. (2020). Impact of lockdown on learning status of undergraduate and postgraduate students during COVID19 pandemic in West Bengal, India. Children and Youth Services Review, 116, 105194.

Kerres, M. (2020). Against all odds: Education in Germany coping with Covid-19. Postdigital Science and Education, 2(3), 690-694. 
Kitua, D. M. (2012). Factors influencing the use of the internet in learning among Bachelor of Education (Arts) Distance Learners: a case of the Meru Extra Mural Centre, University of Nairobi (Doctoral dissertation, University of Nairobi, Kenya).

Kubai, J. (2011). Factors influencing health workers' satisfaction with training by Distance Learning Mode: the case of AMREF Training Centre in Nairobi (Doctoral dissertation, University of Nairobi, Kenya).

Levin, S., Fulginiti, A., \& Moore, B. (2018). The perceived effectiveness of online social work education: Insights from a national survey of social work educators. Social Work Education, 37(6), 775-789.

Levine, A. (2018). Privatization in higher education. In Privatizing education (pp. 133-148). Routledge.

Lorikiriki, A. L. (2016). Factors influencing guidance and counseling programme in the integration of learners with visual impairments and strategies for its enhancement in public primary schools in Turkana South Sub-County, Turkana County, Kenya (Doctoral dissertation, Egerton University).

Mbithi, B. M. (2013). Influence of financial transactions through mobile phones on the growth of Safaricom agents in Kisumu county, Kenya (Doctoral dissertation, University of Nairobi).

Mitra, S., \& Mitra, J. C. Education after covid-19 (real pandemic). : 2020, 187.

Muriungi, D. N. (2015). The contribution of private universities to the development of higher education in Kenya the case of Kenya Methodist University (1997-2013) (Doctoral dissertation, University of Nairobi).

Murphy, M. P. (2020). COVID-19 and emergency eLearning: Consequences of the securitization of higher education for post-pandemic pedagogy. Contemporary Security Policy, 41(3), 492-505.

Nderitu, A. (2013). The effect of time management on academic performance of distance learners: A case of the University of Nairobi distance learners.

Nzuki, P. K., Bowa, O., Gunga, S. O., \& Origa, J. O. (2015). The Relationship Between Perceived Quality Dimensions and Growth in Distance Education: The Case of External Degree Programme of the University of Nairobi, Kenya. International Journal for Innovation Education and Research, 3(2), 87-105.

Oirere, G. G. Month: August 2018.

Owen, J. M. (2020). Program evaluation: Forms and approaches. Routledge.

Rakap, S., Jones, H. A., \& Emery, A. K. (2015). Evaluation of a web-based professional development program (Project ACE) for teachers of children with autism spectrum disorders. Teacher Education and Special Education, 38(3), 221-239. 
Rao, S., \& Krishnan, V. (2014, December). Distance education. In Nitte University, Fourth International Conference on Higher Education: Special Emphasis on Management Education.

Sahu, P. (2020). Closure of universities due to coronavirus disease 2019 (COVID-19): impact on education and mental health of students and academic staff. Cureus, 12(4).

Salloum, S. A., Alhamad, A. Q. M., Al-Emran, M., Monem, A. A., \& Shaalan, K. (2019). Exploring students' acceptance of e-learning through the development of a comprehensive technology acceptance model. IEEE Access, 7, 128445-128462.

Shackman, G. (2018). What is Program Evaluation? A Beginners Guide (Presentation Slides). A Beginners Guide (Presentation Slides)(February 11, 2018).

UŞUN, S. (2016). A review on the program evaluation strategies in distance education. International Journal on New Trends in Education \& Their Implications (IJONTE), 7(3).

Zacharis, N. Z. (2011). The effect of learning style on preference for web- based courses and learning outcomes. British Journal of Educational Technology, 42(5), 790-800.

Zhu, X., \& Liu, J. (2020). Education in and after Covid-19: Immediate responses and long-term visions. Postdigital Science and Education, 2(3), 695-699. 